\title{
Mal común y responsabilidad estatal
}

El desastre natural ocurrido en la región centroamericana hace unos meses, por la gravedad de sus consecuencias y por el alto índice de pérdidas humanas, ha tenido una serie de tratamientos en nuestra sociedad: no han faltado los análisis económicos, sociales y políticos que cuantifican tanto los daños ocasionados en la infraestructura nacional como los saldos negativos para el desarrollo de nuestro futuro cercano. No obstante, lejos de ofrecer un análisis que mida los impactos mutiladores que dejó la tormenta tropical partiendo de cifras o datos estadísticos, queremos detenernos un momento para reflexionar desde un ámbito que por no tener de primera mano la cara cuantificable del problema pierde toda importancia para re-pensar la situación o la condición humana. Nos estamos refiriendo al campo filosófico.

La ventaja que posee la reflexión filosófica es que va más allá de la mera circunstancialidad a la que nos atan muchos análisis económicos, sociológicos o políticos. Una circunstancialidad que no ve más que lo sucedido en el presente. Y el presente, en tanto que "el presente" de esos análisis sociales, se agota en sí mismo, pues su "novedad", su "moda" noticiosa o de hecho susceptible de ser analizado ha perdido su vigencia para atender teóricamente la condición humana en su globalidad. La filosofía, en cambio, o la antropología filosófica, se detiene en el problematismo antropológico que desborda cualquier "novedad" o "moda", pues los problemas humanos son perennes por más que acontezcan en situaciones particulares, en espacios y tiempos concretos. Pero si bien es cierto que la reflexión filosófica parte de la concreción, aquélla intenta no quedar atrapada por las seducciones de lo coyuntural o el inmediatismo. El sufrimiento humano trasciende los casos particulares porque su eventualidad constante nos invita a reflexionar sobre su presencia permanente con nosotros, su presencia en nuestro mundo.

El caso específico en Centroamérica en donde la tormenta tropical dejó más de diez mil muertos hace unos meses, continúa teniendo actualidad para los análisis y las reflexiones no sólo porque ha sido un evento reciente, sino, y sobre todo, porque ha patentizado una vez más cuán frágiles somos los seres humanos y cuán frágiles son nuestras condiciones de existencia. Es entonces cuando el mal, el sufrimiento o el dolor adquieren una fisonomía colectiva y no meramente subjetiva. No es que el dolor individual pierda sentido e importancia para una reflexión; lo que pasa es que el dolor colectivo o el mal común asume la profundidad del sufrimiento mismo porque nos demuestra que es capaz de asediar a cuantos encuentre a su paso. Es así como el mal muestra otra fisonomía muy ligada a la anterior: su permanencia ante nosotros. Ahora bien, el hecho que esté ante nosotros, el hecho de que el mal se convierta en "anónimo" — son miles o cientos de personas las que sufren-; el hecho de que el sufrimiento haya perdido en estos casos la subjetividad concreta (soy "yo" el que padezco; eres "tú" la que no encuentras alivio) no quiere decir que la indiferencia o el olvido nos deba abrumar. La fisonomía colectiva del mal en nuestros espacios geográficos, en nuestra vida diaria, revierte positivamente aquello que ya Levinas había pensado en su primera época intelectual: el sufrimien-

1. Comentario elaborado por Sajid Alfredo Herrera, jefe del Departamento de Filosofía de la Universidad Centroamericana "José Simeón Cañas". 
to, sobre todo el físico, no es algo ajeno al individuo sino que reafirma su propia individualidad o su propia realidad en la medida que no puede escaparse de él, queda en su intimidad ${ }^{2}$. Y lo revierte no en el sentido de desmentir esa afirmación levinasiana, sino en el sentido de ampliar su intencionalidad semántica y filosófica. El sufrimiento repercute más allá de mi intimidad; el sufrimiento, entonces, se hace común, se hace social, reafirma la condición humana en su conjunto.

Vistas así las cosas, es decir, partiendo de la tragedia de la tormenta tropical, parecería que el problema del mal o del sufrimiento humano - con su fisonomía colectiva- no tendría más que una raíz "natural", es decir, se convertiría en un producto azaroso o causal de los mismos dinamismos naturales, ante los cuales la impotencia humana se somete inevitablemente - en aquellos casos en los que no se ha podido controlarla técnica y científicamente- a resultados desastrosos. De hecho, es así como, para algunos pensadores del siglo XIX (tal es el caso de Feuerbach), sostenían que en ese sentimiento de impotencia humana ante los designios de la naturaleza era como había iniciado el fenómeno mítico-religioso en las culturas. Un fenómeno simbólico cuya finalidad era ofrecer una explicación al problema del mal en el mundo. De esa manera iniciaba la traslación de los atributos humanos a los eventos naturales en grado superlativo.

Pero aún más. Podría irse más lejos: desde posturas metafísicas se podría argumentar que el origen del mal o del sufrimiento humano se encontraría en la misma imperfección de la "naturaleza humana". El mal sería entonces "privación", o como lo dice Leibniz, siguiendo a Agustín de Hipona, “... la raíz del mal está en la nada, es decir, en la privación o limitación de las criaturas, que Dios remedia graciosamente mediante el grado de perfección que le place dar"3. Continuando la tradición de la filosofía elaborada en el mundo cristiano, este filósofo alemán (Leibniz) argumentará que el mal no es querido por Dios pero sí será permitido

desde que el ser humano es una criatura imperfecta. Sin embargo, el consuelo se hallaría justificado en los mismos planes divinos: Dios sabría cómo compensar el mal en el mundo, sacando de él un bien mayor. No quedaría más, entonces, que la esperanza en un bien resultante de todo sufrimiento que encontremos a nuestro paso.

Empero, ni el individualismo ni el naturalismo a secas y ni una teodicea de raigambre racionalista pueden responder en su totalidad al problema que nos ocupa. Ya observamos que el sufrimiento humano si bien puede ser enfocado con absoluta legitimidad desde posturas existencialistas, como una característica definitoria del ser humano, no es suficientemente satisfactoria por dejar al margen el carácter social del mismo. Con un naturalismo a secas ocurre lo mismo. No hay duda que muchos eventos naturales son imprevistos; otros producen mucho más daño y dolor que los mismos males ocasionados por los seres humanos. De otros tantos desconocemos sus orígenes, causas o lugares donde se producen. Por lo que ante esa realidad irremediable nos queda, en parte, reconocer nuestra cortedad cognoscitiva y práxica. Pero también nos queda el hecho que hoy en día no vivimos tan aislados y sin ningún medio técnico-científico con el cual pueda investigarse, aprender de la experiencia histórica, prevenir o, si es posible, remediar de alguna forma los efectos de esos males en la sociedad. Además, no vivimos en estado natural de salvajes - como lo pensaron algunos-, sino bajo la protección de las instituciones creadas por los Es-

2. E. Levinas, El tiempo y el otro, Barcelona: Paidós, 1993, pp. 109-110.

3. G. W. Leibniz, Discurso de metafísica, Madrid: Alianza editorial, 1982, No. 30, p. 95. 
tados. Bajo ellas habrá —al menos eso es lo que se esperaría - un grado de responsabilidad para con los habitantes de una región determinada.

La teodicea de raigambre racionalista tiene también sus desventajas ante esta situación. Su reflexión metafísica nos obliga a desligamos en el análisis de las circunstancias que rodean al ser humano. Focalizamos la raíz del problema en un mundo transfísico, en un sujeto o una entidad que está desvinculada de los asuntos capitales que conciernen a cualquier ser humano. Somos partícipes del mal por nuestra imperfección; sin embargo, fuimos creados de esa manera porque no podíamos asemejarnos a nuestro creador. Ése es el precio que tendríamos que pagar para manifestar la bondad de Dios. Este será el argumento de la teodicea medieval y moderna. Un argumento que, según sus exponentes, no podía escrutarse racionalmente más allá de lo enunciado porque no estamos capacitados para comprender dicho misterio. En otras palabras, estaríamos transitando del plano filosófico al plano de la fe. Pero como quiera que sea, esta argumentación no ofrecería mayores soluciones que la de resignarnos ante esta realidad inexorable. De ahí las graves consecuencias que se han derivado a nivel social y político con este tipo de fundamentaciones. Y no es que la filosofía esté capacitada para ofrecer una solución a éste o a otras problemáticas. De hecho, nos enfrentamos a una situación muy grave en la cual no sólo existe impotencia ante padecer el mal, sino impotencia ante pensar e inquirir sobre el mismo con la hondura necesaria. Sin embargo, si lográsemos que esta argumentación se despojara de elementos metafísicos y la volviésemos más secular, más "intramundana" como diría Zubiri, es posible encontrar al menos ciertas salidas a esta inquietante tarea.

Si orientamos nuestra reflexión al mal en nuestro mundo, desde nuestro mundo y observando su fisonomía colectiva, nos daríamos cuenta de que en muchos acontecimientos naturales interviene constantemente la responsabilidad humana cuya actuación se cristaliza en el olvido, la despreocupación o en las ineficientes políticas estatales de prevención de desastres, epidemias o destrucción del entomo ecológico. Sobre todo con aquellos acontecimientos naturales que se producen con cierta regularidad en algunas zonas por diversos motivos y de los cuales se tiene conocimiento por la experiencia histórica. Normalmente achacamos la responsabilidad de los problemas sociales, de los cuales sabemos que tienen un origen humano, a ciertas instituciones sociales o al Estado; no obstante, cuando nos enfrentamos ante males comunes como una tormenta tropical, un terremoto o una epidemia, solemos fijar nuestra mirada hacia otros factores que disuaden ciertas responsabilidades estatales.

Una mirada más atenta de la situación nos conduce a no caer en juicios o prácticas disuasivas. Como ha sostenido Antonio González dentro de la tradición zubiriana, en la vida social, los "otros" intervienen en mi vida y en esa intervención, sus actos pueden producir efectos tanto agradables como nocivos para nosotros, los cuales podemos denominar "bienes" o "males" elementales respectivamente 4 . Esos "otros" no serían más que las "instituciones sociales" (familia, escuela, asociaciones, empresas, organismos, etc.) o el Estado mismo. No nos constituimos entonces en sujetos humanos de una manera solitaria; los "otros" dejan una huella en nuestra realidad (alimentándonos, protegiéndonos, educándonos, etc.). Pero también esa huella en nuestra realidad implica la privación o negación de ciertos bienes o libertades básicas con las cuales nuestra realidad se haría efectiva. Por tanto, en ese acto de privación o negación es que podemos hablar de responsabilidad humana para con los congéneres. $Y$ es ahí que, dentro de una convivencia social, ciertas instituciones sociales o el Estado mismo cumplen algunas tareas esenciales en búsqueda del mayor bienestar colectivo y de aminorar o eliminar el malestar.

Bajo tales circunstancias, no es suficiente apelar al argumento de la existencia de zonas de desastres naturales "conocidas" como el mejor esfuerzo y el "único" para realizar proyectos que solucionen los males de la población. Ello sería atenerse siempre a las consecuencias y no indagar más allá de los problemas. Es indispensable la creación de unas condiciones materiales de existencia mínimamente humanizantes que permitan la plena realización de los individuos. Por ende, si en el mal o sufrimiento subjetivo hay, en muchas ocasiones, una participación real y contundente de la responsabilidad humano-social, ya no digamos en el mal de fisonomía colectiva. Una responsabi-

4. A. González, Estructuras de la praxis. Ensayo de una filosofía primera, Madrid: Trotta, 1997, pp. $104-106$. 
lidad que se manifiesta a través de la donación o del rechazo; a través de otorgar o negar a "los más" - la población- los bienes y medios necesarios para una vida con mayor dignidad.

No compartimos un argumento esgrimido por Norberto Bobbio ${ }^{5}$ cuando sostiene que en la lógica secular del problema del mal no debemos buscar un "culpable", pues de ser así nos moveríamos en la tradición antigua y popular de buscar para cada sufrimiento un culpable, un chivo expiatorio. Desde su perspectiva, la búsqueda de un culpable para asignarle su correspondiente castigo tiene su origen en la confusión del Mal Pasivo con el Mal Activo. El primero es el mal sufrido; el segundo, el cometido. La cultura popular siempre ha hecho de ambos criterios del mal una unidad indisoluble: al mal activo le sigue el mal pasivo, es decir, a una culpa le sigue el sufrimiento, lo cual es remediado por un castigo. En el caso, dirá Bobbio, de un planteamiento laico o secular del problema del mal, la aplicación de esta unidad no sirve de mayor cosa, pues el sufrimiento producido por los desastres naturales, aunque haya cierta culpa por parte de algunos seres humanos, si continuamos investigando más allá llegaremos a la conclusión de que casi siempre el factor originante del problema ha sido un evento natural. Y un evento natural es sólo eso: un fenómeno y por ello pierde cualquier apelativo moral (un evento natural no puede ser justo o injusto como una guerra producida por los humanos).

Pero resulta que aunque el grado de responsabilidad humana en un evento natural, que ha oca- sionado desastres en vida e infraestructura, haya sido ínfima en comparación con las secuelas o el poder del fenómeno mismo, no impide que señalemos o denunciemos ese ínfimo grado de responsabilidad como recurso mínimo, máxime si se trata del Estado. Si bien ya no sería un factor originante, sí sería un factor coadyuvante. Ciertamente, Bobbio puede estar pensando desde las condiciones del Primer Mundo; no obstante, en países o regiones como las nuestras, la situación es otra en términos de grados de responsabilidad del Estado con respecto a la creación de mejores condiciones de vida para la población. En tal sentido, no es que el Estado sea el culpable del sufrimiento que causan los terremotos, las tormentas tropicales o las enfermedades. Empero, su responsabilidad social en cuanto a desatención a problemas en las comunidades, falta de estrategias preventivas contra epidemias, falta de políticas contra la pobreza económica y la marginación es evidente e interpeladora. Pero ha sido más evidente e interpelador el descuido de estas acciones y otras por parte del Estado durante gran parte de la historia de nuestros países. De ahí que una apelación al sufrimiento humano o al mal común desde una perspectiva subjetivista, naturalista o desde una teodicea, lo único que promovería sería orientar la responsabilidad social de este ente político a otras esferas, lo cual no ayudaría a minimizar los males padecidos por los "más".

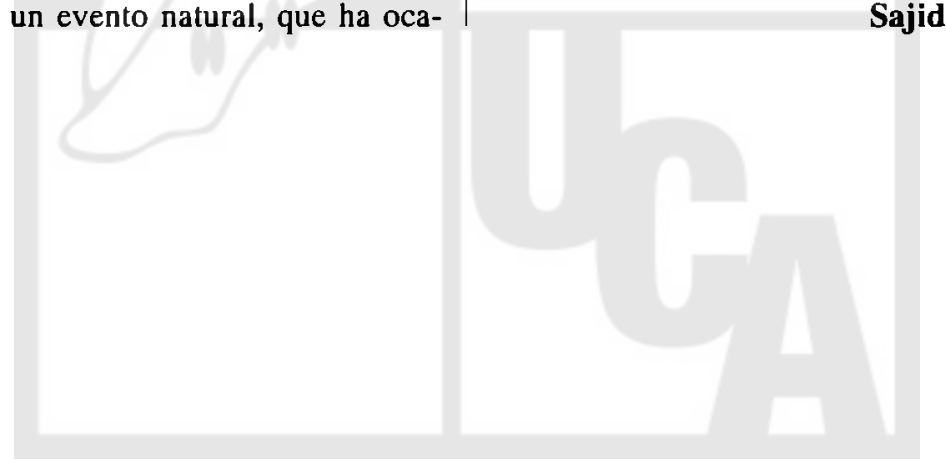

5. N. Bobbio, Elogio de la templanza y otros escritos morales, Madrid: Ediciones Temas de Hoy, 1997, pp. 229 y ss. 